\title{
The use and abuse of office spirometry
}

\author{
*Paul Enright ${ }^{\mathrm{a}}$ \\ a Professor of Medicine, The University of Arizona, Tucson, Arizona, USA
}

Received 20th September 2008; accepted 23rd September 2008; online 29th October 2008

\section{Summary}

Spirometry programs (outside of primary care settings) designed to detect COPD in the general adult population are not justified, since the true positive yield (airway obstruction with an $\mathrm{FEV}_{1}$ below $60 \%$ predicted) is very low, and the false positive rate is very high. How ever, spirometry is greatly under-utilised by GPs who often prescribe inhalers for patients haphazardly. Inhalers for COPD are expensive and risk serious side-effects, so they should not be prescribed for current or former smokers without confirming severe airway obstruction. A large program in Finland has shown that some GPs can perform good quality spirometry. If good quality spirometry is not available in the GP's office, patients should be referred to a local resource for pre- and post-bronchodilator spirometry. More studies are needed to show that GPs use spirometry results systematically to make decisions which truly benefit their patients with asthma or COPD.

(c) 2008 General Practice Airways Group. All rights reserved.

P Enright. Prim Care Resp J 2008; 17(4): 238-242.

doi:10.3132/pcrj.2008.00065

Keyw ords spirometry, case-finding, screening, reliability, primary care, COPD, asthma, $\mathrm{FEV}_{1} / \mathrm{FVC}$

See papers by Tuomisto et al (page 226) and

Rytila et al (page 232)

\section{Introduction}

In this issue of the PCRJ, two papers from Finlanddescribe the surprising success of programs to promote the widespread use of spirometry in the offices (consulting rooms) of primary care practitioners. ${ }^{1,2}$ Similar efforts in other countries have not been successful, despite local pulmonary specialists providing free training, and drug companies providing free spirometers and supplies. ${ }^{3.7}$ The three most common evidence-based indications for office spirometry are: to detect COPD; to determine the severity of asthma; and to measure the response to asthma medications.

\section{Screening spirometry is a waste of resources}

For more than 30 years, pulmonary specialists have been trying to get primary care practitioners to "Detect COPD Early," but we still don't have the evidence that these efforts help more patients than they hurt. Public campaigns in the United States (USA) tell smokers to "Test Your Lungs; Know Your Numbers." Instead, I think that patients should be told to "Blow Hard (into a spirometer) Before You Suck Deeply" (frop an expensive inhaler). GPs should not even consider Oprescribing an inhaler for COPD until severe airway obstruction has been confirmed by spirometry.

Hundreds of thousands of smokers have received spirometry testing in national campaigns which have produced tens of thousands of "cases" of COPD. However, according to extensive literature reviews, the Agency for Healthcare Research and Quality (AHRQ) group in the USA has concluded that such programs are not justified. ${ }^{8,9}$ In fact, spirometry done in medical care settings for patients with chronic respiratory symptoms (at high risk for lung disease) is true "case finding", whereas "screening" spirometry is done outside of a physician's office or hospital, often for anyone who is interested in the test (and thus at low risk for lung disease). ${ }^{10,11}$ Screening spirometry projects are often said to be done to "increase awareness" of COPD, but considerable harm can occur when the person is inappropriately told that the results are abnormal. ${ }^{12,13}$ Misclassification of spirometry results commonly occurs due to poor coaching, poor inspiratory or expiratory effort, an inaccurate spirometer, or inappropriate interpretation of the spirometry tracing.

Smokers are not more likely to quit smoking successfully when faced with abnormal spirometry results. ${ }^{14,15}$ All smokers, regardless of spirometry results, should be helped by primary

* Corresponding author: Dr Paul Enright, Professor of Medicine, The University of Arizona, Tucson, Arizona, USA. E-mail: LungGuy@aol.com 
care practitioners to quit smoking - and this help should include the prescription of bupropion or varenicline for those who have failed less expensive interventions. ${ }^{16}$ So, prompting smoking cessation is not a valid rationale for promoting screening spirometry; you should not need a "stage prop" (abnormal test result) to convince a smoker to allow you to help him or her quit smoking permanently.

\section{False positive rates for "mild COPD" are very high}

Somehow, COPD guidelines published by pulmonary specialists during the past decade became biased towards increasing prescriptions for expensive inhalers. Patients with a normal forced expiratory volume in one second $\left(\mathrm{FEV}_{1}\right)$ were classified as having mild COPD (GOLD Stage 1) if their $\mathrm{FEV}_{1} /$ forced vital capacity (FVC) ratio was below $0.70 . .^{17,18}$ But the $\mathrm{FEV}_{1} / \mathrm{FVC}$ ratio decreases with age in healthy neversmokers, so the false positive rate for airway obstruction (and thus (OPD) - as defined by several pulmonary professional societies - increases above the age of 50 and is very high in patients aged 70 years or above. ${ }^{19-21}$ The fifth percentile from spirometry reference equations derived from a healthy population sample should be used to determine the lower limit of the normal range (LLN) for both the $\mathrm{FEV}_{1} / \mathrm{FVC}$ ratio and for the $\mathrm{FEV}_{1}$ itself. ${ }^{22}$ The age and gender-corrected LLNS are calculated automatically by the majority of commercially available spirometers, so there is no need to use the faulty 0.70 ratio in practice.

There is also no need to detect COPD "early" because there is no evidence that GOLD Stage 1 is a disease or a risk factor. ${ }^{23,24}$ The risk of a subsequent rapid decline in lung function in an adult smoken with airway obstruction is substantially increased only after their $\mathrm{FEV}_{1}$ has fallen to below about $65 \%$ predicted. ${ }^{25}$

About one-third of adult smokers with airway obstruction found during screening spirometry will not have airway obstruction ten minutes after inhaling a fast-acting bronchodilator. ${ }^{26}$ By definition, COPD is then ruled out. This finding increases the probability of asthma in those with asthma-like symptoms. Up to a half of adults with asthma are current smokers in some countries, ${ }^{27,28}$ and their asthma will be more easily controlled if they successfully quit smoking. ${ }^{29}$ Primary care practitioners (outside of Finland) rarely have the time to repeat spirometry after salbutamol inhalation, so it follows that they should not make a diagnosis of COPD in a patient with mild to moderate airway obstruction without referring these patients for post-bronchodilator spirometry. ${ }^{30}$ Differentiating asthma from COPD is important because asthma infrequently responds to the anti-cholinergic inhalers often prescribed for COPD, and the prognosis for asthma is much better.

\section{Mild restriction is not early COPD}

"Mild restriction" is a non-specific, non-diagnostic, spirometry result. It is often due to poor inspiratory or expiratory effort, not measuring the patient's height properly (men often exaggerate their height when asked), use of inappropriate reference values (e.g. using Caucasian reference values when testing a black patient), or using an interpretation scheme which is not evidence-based. A low FVC without a low $\mathrm{FEV}_{1} / \mathrm{FVC}$ ratio is often interpreted as restriction, but at least half of such patients have normal lung volumes when referred to a pulmonary function laboratory and tested in a body plethysmograph. ${ }^{31}$ Clinical research is needed to determine the clinical correlates of this non-specific spirometry pattern, much of which is probably due to obesity or poor effort. There is no evidence that mild "spirometric restriction" is due to "air trapping" secondary to "small airways disease" or early COPD in patients who would benefit from treatment with inhalers. ${ }^{13}$ I would not use spirometric " restriction" for medical decision-making, or as an indication for referring the patient for complete pulmonary function testing, unless, the FVC is repeatably below $60 \%$ predicted, or the patient has an abnormal chest $x$-ray, or has dyspnoea on exertion, but is not obese.

In order to minimise misclassification of spirometry interpretations, we should learn to accept uncertainty when the results are near the LLN (borderline abnormal), the quality of the test was poor (due to sub-maximal efforts), and when post-bronchodilator results are unavailable. ${ }^{11}$

\section{Yet spirometry is greatly under-utilised}

According to studies in the USA, the majority of people reporting a doctor-diagnosis of COPD have never had spirometry testing to confirm the diagnosis., ${ }^{4,32}$ There was a wide geographic variation in the use of spirometry to confirm $\mathrm{COPD},{ }^{33}$ and this is probably true between and within many other countries. This practice is akin to prescribing antihypertensive medications without measuring blood pressure... While they may be smokers with a chronic cough and perhaps some dyspnoea due to poor conditioning, many of these patients do not have airway obstruction. ${ }^{34}$

\section{Should GPs buy a spirometer or simply order spirometry tests?}

In most countries, a minority of primary care practitioners have purchased a spirometer, and few have actually used it during the past month. ${ }^{3,5,35,36}$ Some GPs use a spirometer several times a month, but many of the tests fail the standard goals for good quality. ${ }^{37}$ In the USA, a nurse or technologist performs the spirometry tests (not the doctor), but the majority of these staff have not been trained to perform spirometry tests properly, and post-bronchodilator spirometry 
is almost never done due to time constraints. ${ }^{38}$

A few GPs purchase a spirometer and use it for the majority of their patients who have an indication for spirometry - smokers over age 40 with dyspnoea, or patients with poorly controlled asthma. These "early adopters" report that the spirometry results often assist medical decisionmaking. ${ }^{39-41}$ However, the majority of GPs who are given a spirometer and receive training no longer use spirometry after the first few months. ${ }^{6}$

For most GPs in urban and suburban settings, the best solution may be for a third-party expert to perform the necessary spirometry tests. ${ }^{42-45}$ In the USA, about half of the spirometry tests done around the time of the initial diagnosis of COPD are done in a traditional pulmonary function laboratory, ${ }^{4}$ but this approach is greatly under-utilised, perhaps due to long delays, inconvenience, or excessive cost. Regularly-scheduled "free clinics" in convenient locations (such as neighbourhood pharmacies or community centres) have successfully been used in Poland. ${ }^{46}$ Another approach, which has proved to be successful in some locations, is for an itinerant nurse or certified technologist to schedule monthly visits to the GP's office to test patients who have an indication for spirometry. ${ }^{743}$ More than $80 \%$ of the tests done by certified and skillful technologists meet ATS/ERS quality goals.

\section{A normal peak flow rules out clinically important COPD}

As described by Rytila et $\mathrm{al}^{2}$ and others ${ }^{47}$ lower false positive rates will be obtained - with no loss of sensitivity for smokers who may benefit from a COPD inhaler - if inexpensive pocket spirometers are used to excludde substantial airway obstruction in primary care settings. Furthermore, inexpensive mechanical peak expiratory flow (PEF) meters can be used; a ground-breaking report from the PLATINO and BOLD studies demonstrates that a normal PEF measurement can confidently exclude GOLD Stage III or more severe COPD in smoking adults. ${ }^{48}$ This stepped approach is efficient because only the fraction of patients with a low PEF or an $\mathrm{FEV}_{1}$ below $60 \%$ predicted need a referral to a specialty service for good quality pre- and post-bronchodilator spirometry to confirm postbronchodilator airway obstruction.

\section{Drugs for COPD?}

The inhalers prescribed for COPD are very expensive and risk serious side-effects, including death by arrhythmia, ${ }^{49-53}$ and thus should not be considered unless an $\mathrm{FEV}_{1}$ below $50 \%$ predicted has been confirmed by good quality spirometry testing. ${ }^{8}$ The effectiveness of COPD inhalers has not been weighed against the costs and risks of these drugs. ${ }^{54}$ There is an imbalance of information in the promotion of these inhalers. More than 5 billion Euros worth of inhalers are currently sold worldwide each year, providing an irresistible financial imperative for drug companies to expand this market. Industry-sponsored clinical trials are likely to be biased by their inclusion/exclusion criteria, comparators, choice of outcome measures, analysis details, and conclusions.

I worry that many smokers who are prescribed an inhaler for COPD feel that they don't need to try to stop smoking. About half of the participants in large COPD clinical trials remain current smokers throughout the study. ${ }^{55,56}$ In my opinion, efforts by health care professionals to promote inhaler compliance in such patients should be re-directed to help them to quit smoking.

\section{Spirometry for patients with asthma}

Tuomisto and coworkers from Finland report in this issue that good quality flow-volume curves were obtained about $80 \%$ of the time by primary care-doctors who referred patients with asthma to a pulmonary specialist. ${ }^{1}$ This very high success rate in meeting ATS goals for good quality spirometry is much better than previously reported in other primary care settings. ${ }^{42,56.5} \mathrm{~V}$ How ever, success in meeting the ATS goal of $5 \%$ repeatability of $\mathrm{FEV}_{1}$ was not measured by this study, ${ }^{1}$ yet is a majorfactor when evaluating bronchodilator and treatment responses in patients with asthma. For example, an FEVP increase of $10 \%$ is often a clinically important change, but is within the noise of measurement in some settings.

Normal spirometry does not rule out asthma in a patient with a history of asthma-like symptoms or in a patient taking asthma controller medications; ${ }^{58}$ however, spirometry is often useful for excluding the possibility of COPD in adult smokers with asthma-like symptoms (as discussed above). ${ }^{11}$ Spirometry (i.e. a low $\mathrm{FEV}_{1}$ ) will sometimes reveal that asthma is more poorly controlled than suggested by the frequency of symptoms and use of a rescue inhaler reported by the patient. ${ }^{59}$ A low $\mathrm{FEV}_{1}$ is also a strong predictor of a subsequent asthma exacerbation. ${ }^{60,61} \mathrm{FEV}_{1}$ can be measured accurately even during acute asthma attacks ${ }^{62}$ and helps to determine the need for hospitalisation. The ability of primary care physicians to utilise the $\mathrm{FEV}_{1}$ to make better clinical decisions and improve clinical outcomes in patients with asthma (when compared to reliance on the clinical history and peak expiratory flow) remains to be studied.

\section{Conclusion}

In summary, some general practitioners can successfully use office spirometry to detect severe COPD and asthma which is less well controlled than indicated by symptoms; however, many other GPs should refer patients with respiratory symptoms to a local service which can provide good quality pre- and post-bronchodilator spirometry and interpretations. 


\section{Conflict of interest declaration}

During the past three years, the author has received payments for consulting on spirometry quality assurance programs for phase III clinical trials from Pfizer (varenicline for smoking cessation in patients with COPD) and InterMune (for patients with idiopathic pulmonary fibrosis). He has received no consulting or travel expense reimbursement from any companies which make pulmonary function equipment or spirometers.

\section{References}

1. Tuomisto L, Jarvinen V, Laitinen J, et al. Asthma programme in Finland: the quality of primary care spirometry is good. Prim Care Resp J 2008;17(4):22631. doi:10.3132/pcri.2008.00053

2. Rytila $\mathrm{P}$, Helin $\mathrm{T}$, Kinnula V. The use of microspirometry in detecting lowered FEV1 values in current or former cigarette smokers. Prim Care Resp J 2008; 17(4):232-7. doi:10.3132/pcrj.2008.00058

3. Boffin N, Van der Stighelen V, Paulus D, Van Royen P. Use of office spirometers in Flemish general practice: results of a telephone survey. Monaldi Arch Chest Dis 2006;65:128-32.

4. Han MK, Kim MG, Mardon R, et al. Spirometry utilization for COPD: How do we measure up? Chest 2007;132:403-09.

5. Johns DP, Burton D, Walters JAE, Wood-Baker R. National survey of spirometer ownership and usage in general practice in Australia. Respirology 2006; 11:292-8.

6. Lusuardi M, De Benedetto F, Paggiaro P, et al. A randomized controlled trial on office spirometry in asthma and COPD in standard general practice. Chest 2006;129(4):844-52.

7. Walters JA, Hansen EC, Johns DP, et al. A mixed methods study to compare models of spirometry delivery in primary care for patients at risk of COPD. Thorax 2008;63:408-14.

8. Qaseem A, Snow V, Shekelle P, et al. Diagnosis and management of stable chronic obstructive pulmonary disease: a clinical practice guideline from the American College of Physicians. Ann Intern Med 2007;147(9):633-8.

9. Lin K, Watkins B, Johnson T, et al. Screening for chronic obstructive pulmonary disease using spirometry: summary of the evidence for the U.S. Preventive Services Task Force. Ann Intern Med 2008;148(7):535-43.

10. Ferguson GT, Enright PL, Buist AS, Higgins $M W$. Office spirometry for lung health assessment in adults: A consensus statement from the National Lung Health Education Program. Chest 2000;117:1146-61.

11. Enright PL, Studnicka M, Zielinski J. Spirometry to detect and manage COPD and asthma in the primary care setting. Eur Respir M on 2005;31:1-14.

12. Enright P. Does screening for COPD by primary care physicians have the potential to cause more harm than good? Chest 2006;129(4):833-5.

13. Enright PL. Flawed interpretative strategies for lung function tests harm patients. Eur Respir J 2006;27(6):1322-3.

14. Buffels J, Degryse J, Decramer M, et al. Spirometry and smoking cessation advice in general practice: a randomized clinical trial. Respir Med 2006; 100:2012-17.

15. Wilt TJ, Niewoehner D, Kane RL, MacDonald R, Joseph AM. Spirometry as a motivational tool to improve smoking cessation rates: a systematic review of the literature. Nicotine Tob Res 2007;9:21-32.

16. Tønnesen P, Carrozzi L, Fagerström KO, et al. Smoking cessation in patients with respiratory diseases: a high priority, integral component of therapy. Eur Respir J 2007;29(2):390-417.

17. GOLD. Workshop report, global strategy for diagnosis, management and prevention of COPD: http://www.goldcopd.com/; 2007 No. Workshop report, global strategy for diagnosis, management and prevention of COPD.

18. ATS/ERS Task Force: Standards for the diagnosis and treatment of patients with COPD: a summary of the ATS/ERS position paper. Eur Respir J 2004;23:932-46.

19. Hnizdo E, Glindmeyer HW, Petsonk EL, Enright P, Buist AS. Case definitions for chronic obstructive pulmonary disease. COPD 2006;3:1-6.
20. Schermer TR, Smeele IJ, Thoonen BP, et al. Current clinical guideline definitions for airflow obstruction leads to substantial overdiagnosis of COPD in primary care. Eur Respir J 2008;32:945-52.

20a. Schermer TRJ, Quanjer PH. COPD screening in primary care: who is sick? Prim Care Resp J 2007;16(1):49-53. doi:10.3132/pcri.2007.00012

21. Swanney MP, Ruppel G, Enright PL, et al. Using the lower limit of normal for the FEV1/FVC ratio reduces the misclassification of airway obstruction. Thorax 2008; September 11 Epub ahead of print.

22. Pellegrino R, Brusasco V, Viegi G, et al. Definition of COPD: based on evidence or opinion? Eur Respir J 2008;31(3):681-2.

23. Pinto-Plata VM, Celli-Cruz RA, Vassaux C, et al. Differences in cardiopulmonary exercise test results by ATS/ERS-GOLD stage categories and gender. Chest 2007;132:1204-11.

24. Enright PL. GOLD stage I is not a COPD risk factor. Thorax 2007;62(12):1107.

25. Scanlon PD, Connett JE, Waller LA, Altose MD, Bailey WC, Buist AS. Smoking cessation and lung function in mild-to-moderate chronic obstructive pulmonary disease. The Lung Health Study. Am J Respir Crit Care Med 2000; 161(2 Pt 1):381-90.

26. Perez-Padilla R, Hallil PC, Vazquez-Garcia JC. Impact of bronchodilator use on the prevalence of COPD in population-based samples. COPD 2007;4:113-20.

27. Wakefield M, Ruffin R, Campbell D, Roberts L, Wilson D. Smoking-related beliefs and behaviour among adults with asthma in a representative population sample. Aust N ZJ Med 1995;25(1):12-17.

28. Hylkema MN, Sterk PJ, de Boer WI, Postma DS. Tobacco use in relation to COPD and asthma. Eur Respir J 2007;29(3):438-45.

29. Overcoming steroid insensitivity in smoking asthmatics. Curr Opin Investig Drugs 2008;9(5):470-7.

30. Calverley Pulfilling the promise of primary care spirometry. Editorial. Eur Respir 2008;31:8-10.

31. Vandevoorde J, Verbanck S, Schuermans D, et al. Forced vital capacity and forced expiratory volume in six seconds as predictors of reduced total lung capacity. Eur Respir J 2008;31(2):391-5.

32. Lee $T A$, Bartle $B$, Weiss KB. Spirometry use in clinical practice following diagnosis of COPD. Chest 2006;129(6):1509-15.

33. Joo MJ, Lee TA, Weiss KB. Geographic variation of spirometry use in newly diagnosed COPD. Chest 2008;134(1):38-45.

34. Walker PP, Mitchell P, Diamantea F, Warburton CJ, Davies L. Effect of primarycare spirometry on the diagnosis and management of COPD. Eur Respir J 2006; 28(5):945-52.

35. Kaminsky DA, Marcy TW, Bachand M, Irvin CG. Knowledge and use of office spirometry for the detection of chronic obstructive pulmonary disease by primary care physicians. Respir Care 2005;50(12):1639-48.

36. Derom E, van Weel C, Liistro G, et al. Primary care spirometry. A review. Eur Respir J 2008;31:197-203.

37. Walters JA, Hansen EC, Walters EH, Wood-Baker R. Under-diagnosis of chronic obstructive pulmonary disease: a qualitative study in primary care. Respir Med 2008;102(5):738-43.

38. Schermer TR, Jacobs JE, Chavannes NH, et al. Validity of spirometric testing in a general practice population of patients with chronic obstructive pulmonary disease (COPD). Thorax 2003;58(10):861-6.

39. Chavannes N, Schermer T, Akkermans R, et al. Impact of spirometry on GPs' diagnostic differentiation and decision-making. Respir Med 2004; 98(11):1124-30.

40. Dales RE, Vandemheen KL, Clinch J, Aaron SD. Spirometry in the primary care setting: influence on clinical diagnosis and management of aifflow obstruction. Chest 2005;128(4):2443-7.

41. Yawn BP, Enright PL, Lemanske RF Jr, et al. Spirometry can be done in family physicians' offices and alters clinical decisions in management of asthma and COPD. Chest 2007;132(4):1162-8.

42. Cooper BG. Limitations to spirometry being performed in "the office." Chronic Respir Dis 2005;2:113-15. 
43. Hassett $R$, Meade $K$, Partridge MR. Enhancing the accuracy of respiratory diagnoses in primary care: a report on the establishment of a Community Respiratory Assessment Unit. Prim Care Resp J 2006;15:354-61. doi:10.1016/j.pcrj.2006.10.003

44. Poels PJ, Schermer TR, Schellekens DP, et al. General practitioners' needs for ongoing support for the interpretation of spirometry tests. Eur J Gen Pract 2007;13(1):16-19.

45. Enright P. Provide GPs with spirometry, not spirometers. Thorax 2008; 63(5):387-8.

46. Zieliñski J, Bednarek M; Know the Age of Your Lung Study Group. Early detection of COPD in a high-risk population using spirometric screening. Chest 2001;119(3):731-6.

47. Fonseca JA, Costa-Pereira A, Delgado L, et al. Pulmonary function electronic monitoring devices: a randomized agreement study. Chest 2005;128:1258-65.

48. Perez-Padilla R, Vollmer WM, Vazquez-Garcia JC, Enright PL, Menezes AMB, Buist AS, for the BOLD and PLATINO study groups. Peak Expiratory Flow to Enhance Screening for COPD. Int J Tuberc Lung Dis 2008; In Press.

49. Anthonisen NR, Connett JE, Enright PL, et al. Hospitalizations and mortality in the Lung Health Study. Am J Respir Crit Care Med 2002;166:333-9.

50. Au DH, Curtis JR, Every NR, et al. Association between inhaled beta-agonists and the risk of unstable angina and myocardial infarction. Chest 2002; 123:1964-69.

51. Salpeter SR, Ormiston TM, Salpeter EE. Cardiovascular effects of beta-agonists in patients with asthma and COPD. A meta-analysis. Chest 2004;125:230921.

52. Macie C, Wookdrage K, Manfreda J, Anthonisen N. Cardiovascular morbidity and the use of inhaled bronchodilators. International J COPD 2008;3(1):1-7.

53. Lee TA, Pickard AS, Au DH, Bartle B, Weiss KB. Risk of death associated with medications for recently diagnosed COPD. Ann Intern Med 2008;149:380-90.

54. Guyatt GH, Oxman AD, Kunz R, et al; GRADE Working Group. Going from evidence to recommendations. BMJ 2008;336(7652):1049-51.

55. Calverley PM, Anderson JA, Celli B, et al; TORCH investigators. Salmeterol and fluticasone propionate and survival in chronic obstructive pulmonary disease. $\mathrm{N}$ Engl J Med 2007;356(8):775-89.

56. Pellegrino R, Decramer M, van Schayck CP, et al. Quality control of spirometry: a lesson from the BRONCUS trial. Eur Respir J 2005;26(6):1104-09.

57. Eaton $\mathrm{T}$, Withy S, Garrett JE, et al. Spirometry in primary care practice. The importance of quality assurance and the impact of spirometry workshops. Chest 1999;116:416-23.

58. Wolfenden LL, Diette GB, Krishnan JA, Skinner EA, Steinwachs DM, Wu AW. Lower physician estimate of underlying asthma severity leads to undertreatment. Arch Intern Med 2003;163:231-6.

59. Spahn JD, Cherniack R, Paull K, Gelfand EW. Is FEV1 the best measure of severity in childhood asthma? Am J Respir Crit Care Med 2004;169:784-6.

60. Fuhlbrigge AL, Weiss ST, Kuntz KM, Paltiel D. FEV1 percentage improves classification of severity among children with asthma. Pediatrics 2006; 118:347-355.

61. Tantisira KG, Fuhlbrigge AL, Jonascia J, et al. Bronchodilation and bronchoconstriction: Predictors of future lung function in childhood asthma. J Allergy Clin Immunot 2006;117:1264-71.

62. Silverman RA, flaster E, Enright PL, Simonson SG. FEV1 performance among patients with acute asthma. Chest 2007;131:164-71.

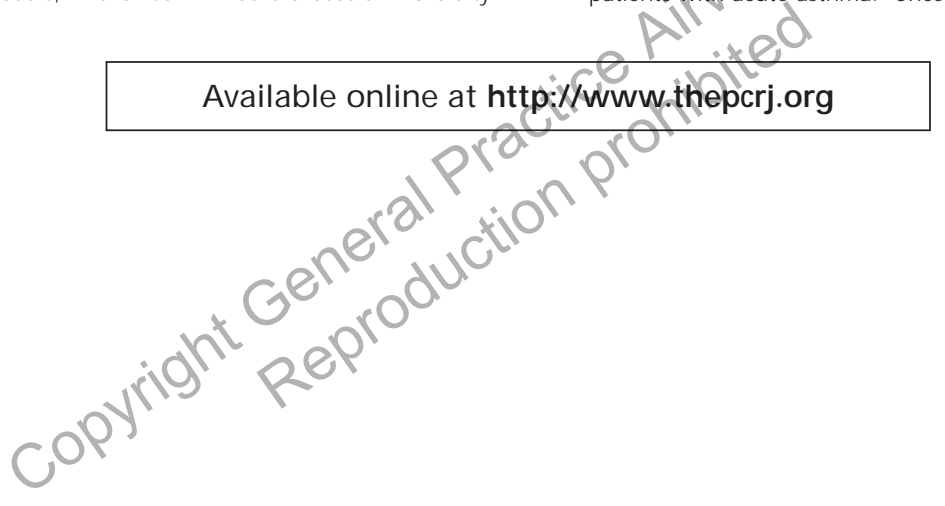

